\title{
Risk Reduction and Real Estate Portfolio Size
}

\author{
Stephen L. Lee and Peter J. Byrne
}

\section{Introduction}

The investigation of the impact that portfolio size has on risk (volatility) is of continuing interest in real estate markets (see Byrne and Lee (1999) for a review). The general approach uses the returns from a sample of properties and then simulates portfolios of various sizes, usually with equal-weighting, and then calculates the average level of risk for each portfolio size. The averaged results usually indicate that an increase in portfolio size is accompanied by a reduction in portfolio volatility and that most of the reduction occurs within the first 20-40 properties, after which any fall in risk level is marginal. The advice to an investor portrayed in these averaged simulation results is to hold a portfolio containing relatively few properties.

It can be argued that this general approach is deficient because an individual investor owns only one portfolio and results based on the average are not really relevant to his/her particular case, which may be substantially different from the average. Indeed a few studies have alluded to the fact that the simulations themselves display a good deal of variability around the mean portfolio risk level, Barber (1991), Cullen (1991) and Byrne and Lee (1999). This is especially so for portfolios of a small size. Thus investors who have relied on the previous studies based on average portfolio results can have little confidence that their portfolio will display the same level of portfolio risk as that suggested by averaged results. In addition, studies based on equal-weighted simulations may be felt to be irrelevant to property portfolios which are typically value-weighted. Indeed the work of Morrell (1993b), Schuck and Brown (1997) and Byrne and Lee (1999) suggests that value-weighted portfolio are sub-optimal because the portfolios have a higher total risk in comparison to equal-weighted portfolios. Simulations, even value-weighted, probably seem unrealistic to most practitioners. Results from actual data would be desirable therefore and yet there is remarkably little empirical evidence based on actual property portfolios. This is in spite of the fact that the few studies in the UK which have used the returns from actual portfolios, Cullen (1991) and Morrell (1993a, 1997), suggest that the amount of risk reduction in real estate portfolios is limited and that a large level of variability exists around the mean portfolio risk level, especially for small sized portfolios. The objective of this paper is to extend this analysis further by studying the affect of portfolio size on risk reduction using actual property data over the period 1981 to 1996.

\section{Risk Reduction}

Markowitz (1952) showed that the variance of a portfolio of $N$ assets is given by:

$$
\sigma_{p}^{2}=\sum_{i=1}^{N} w_{i}^{2} \sigma_{i}^{2}+\sum_{\substack{i=1 \\ j \neq 1}}^{N} \sum_{j}^{N} w_{i} w_{j} \sigma_{i} \sigma_{j} \rho_{i j}
$$

where:

$$
\begin{aligned}
& \sigma_{\mathrm{p}}^{2}=\text { portfolio variance } \\
& \sigma_{\mathrm{i}}^{2}=\text { the variance of asset } i \\
& \rho_{\mathrm{i}, \mathrm{j}}=\text { the correlation between assets } i \text { and } j \\
& \mathrm{~N}=\text { the number of assets. }
\end{aligned}
$$


Equation 1, in the special case where $\sigma_{\mathrm{i}}$ equals the average standard deviation $\bar{\sigma}$ and $\rho_{\mathrm{ij}}$ equals the average correlation coefficient $\bar{\rho}$ for all $i$, becomes:

$$
\sigma_{p}^{2}=\sum_{i=1}^{N} w_{i}^{2} \bar{\sigma}^{2}+\sum_{\substack{i=1 \\ j \neq 1 \\ j \neq i}}^{N} \sum_{i}^{N} w_{i} w_{j} \bar{\sigma}^{2} \bar{\rho}
$$

It will be noted that for any given $w_{i}$, the sum of all $w_{i}$ for $j \neq i$ must equal $\left(1-w_{i}\right)$. Substituting into the last term of equation 2 produces:

$$
\sigma_{p}^{2}=\bar{\sigma}^{2} \bar{\rho}+\bar{\sigma}^{2}(1-\bar{\rho}) \sum_{i=1}^{N} w_{i}
$$

In addition if we assume equal weighting equation 3 simplifies to:

$$
\sigma_{p}^{2}=\bar{\sigma}^{2} \bar{\rho}+\bar{\sigma}^{2}(1-\bar{\rho}) \frac{1}{N}
$$

Equation 4 shows that the total risk (variance) of a portfolio can be broken down into two components. The first component, represented by the first term on the RHS of equation 4, cannot be eliminated by increasing the number of investments in a portfolio. This component of risk is therefore common to all investments and is called systematic or market risk, see Elton and Gruber (1977). In contrast the second term on the RHS of equation 4, can be effectively eliminated by increasing the number of investments in a portfolio. The elimination of this part of total risk will be achieved rapidly, since as $\mathrm{N}$ increases $1 / \mathrm{N}$ approaches zero very quickly. This component of risk is labelled non-market or residual risk. The level of risk reduction that can be achieved in a portfolio is limited, or bounded by, the risk of the market. Hence the reduction in risk within a portfolio of increasing size can only come about by the elimination of the non-market or residual variance inherent in the investment. Two basic methods have been suggested in the literature to measure the impact of size on portfolio risk, the first graphical and the second statistical.

In the graphical approach researchers usually simulate portfolios of increasing size (typically equally-weighted), based on individual data, and calculate the level of risk (standard deviation or variance of returns) for each portfolio. The individual portfolio risks are then averaged and plotted against portfolio size. The resultant graphs typically show an initial rapid decline in average portfolio risk which then tapers away towards some "market" level".

The statistical approach follows much the same procedure with a large number of portfolios of increasing size simulated from individual data from which some measures of the risk are calculated for each portfolio and the resultant values for each portfolio size averaged. The researchers may then display the results graphically and/or more usually employ regression methodology to derive the relationship between the measure of risk and the portfolio size.

\footnotetext{
${ }^{1}$ See for example Jones Lang Wootton (1986); Barber (1991); Cullen (1991); Myer, Webb and Young (1997) and Byrne and Lee (1999) for studies in the property market and Evans and Archer (1968): and Wagner and Lau (1971); Johnson and Shannon (1974); Tole (1982) and Lloyd, Hand and Modani (1981) for studies in equity and bond markets.
} 
The first regression approach adopted in the literature was suggested by Evans and Archer (E\&A) (1968) and simply relates the standard deviation (total risk) of a portfolio to the number of investments held using the following equation:

$$
\sigma=\alpha+\beta(1 / N)
$$

E\&A argue that the regression of total risk (standard deviation) on $1 / \mathrm{N}$ shows the impact of portfolio size on the non-market risk within the portfolio because any fall in the value of total risk must be a consequence the elimination of non-market risk within the portfolio. E\&A found that this model explained $98.6 \%$ of the variability of the mean standard deviation for US stock market securities. Their analysis also showed that the reduction in total risk was substantial up to portfolios of eight to ten securities, after which the standard deviation of the portfolio became asymptotic to the risk of the market.

The second method, suggested by Wagner and Lau (W\&L) (1971), uses the proportion of market risk in a portfolio to indicate the reduction in risk achieved by increasing portfolio size.

W\&L use the Single Index Model (SIM) to determine how much of the variability in returns of a portfolio can be explained by some market index:

$$
\mathrm{R}_{\mathrm{i}}=\alpha_{\mathrm{i}}+\beta_{\mathrm{i}} \mathrm{R}_{\mathrm{m}}+\mathrm{e}_{\mathrm{i}}
$$

where:

$\mathrm{R}_{\mathrm{i}}$ is the return of the portfolio $\mathrm{i}$;

$\mathrm{R}_{\mathrm{m}}$ is the return on the market portfolio;

$\beta_{\mathrm{i}}$ is the index of systematic risk of portfolio $\mathrm{i}$

$\alpha_{i}$, is the intercept coefficient and

$\mathrm{e}_{\mathrm{i}}$ is a random error term, which has an expected value of zero.

The coefficient of determination $\left(\mathrm{R}^{2}\right)$ of such a regression indicates the proportion of variability in returns that can be explained by the market. The amount that is unique or specific to the portfolio itself, the non-market risk, is given by $\left(1-\mathrm{R}^{2}\right)$. A regression of $\mathrm{R}^{2}$ on $1 / \mathrm{N}$ using equation (7) indicates the number of investments to hold to reduce the amount of non-market risk to an 'acceptable' level:

$$
\mathrm{R}^{2}=\alpha+\beta(1 / \mathrm{N})
$$

W\&L using this approach again found that the increase in $\mathrm{R}^{2}$ was substantial up to eight or ten securities after which the gain is marginal. Based on the E\&A and W\&L approaches the initial impression is that security portfolios need have only a few investments to be fully diversified down to the market level.

In the real estate market, using the above approaches, Brown $(1988,1991)$ finds that for equalweighted portfolios "after about ten properties have been included within a portfolio the reduction in risk which can be achieved by holding more properties diminishes dramatically". This supports the findings of E\&A and W\&L. However Brown also acknowledges that this reduction in portfolio risk is likely to be hampered by the indivisibility of individual properties and the preference of fund managers to follow value-weighting schemes in developing their portfolios. Brown finds that value-weighted portfolios are less diversified than equal-weighted portfolios and so would require more properties to bring risk down to the systematic (market) risk level. Using the regression approach of $\mathrm{W} \& \mathrm{~L}$, Brown finds that even assuming an equal- 
weighting scheme it would be necessary hold more than 200 properties to achieve a $R^{2}$ of 95 per cent. Only 45 shares are required to achieve the same level in the UK stock market. The effect of value-weighting would be to require an even greater number of properties (Byrne and Lee, 1999).

However, Tole (1982) suggests that the results of E\&A and W\&L and by association those of Brown can be misleading for investors as they are based on "averaging techniques" essentially designed to obtain satisfactory regressions coefficients. Such averaging, by its nature, reduces the variability of the data and so magnifies the statistical fit of the regressions. It can be argued that previous approaches are potentially flawed because of the fact that an individual investor owns only one portfolio and results based on the average are not really relevant to his/her particular case, which may be substantially different from that average (Newbould and Poon, 1993). Tole (1982) presents a diagram showing that the original data used by E\&A based on 60 simulations for each portfolio size from 1 to 40 securities display a wide variation around the average standard deviation level. The simulation results of Byrne and Lee (1999) suggest a similar picture in the UK property market. Byrne and Lee find that for the 20 asset level there is still a 5\% chance of having a risk level approximately 15-25 percent above the average, depending on the sector or region chosen and the weighting scheme employed. At the 40 asset level the deviation from the average is still 11 to 18 percent. Only at the 200+ asset portfolio is the deviation small enough to be ignored.

When Tole (1982) applied the approach of E\&A to 55 simulated portfolios, without averaging the individual standard deviations, the resulting $\mathrm{R}^{2}$ was only $14 \%$, rather than the $98.6 \%$ found from the "averaged" regressions. Such a low level of statistical fit implies that the confidence an investor can have that their portfolio will behave in the same way as the average is likely to be weak to say the least. Consequence an individual investor who follows the advice contained in previous studies which are based on the results of average portfolio risks may be exposing themselves to potentially much greater risk than they intend. Tole argues that the 'true' measure of risk reduction in a portfolio should not be the "average" but the worst position. This is similar to the argument of McDonald (1975) who suggests most investors see diversification as designed to reduce the "probability of ex post returns being an adverse surprise". Investors who wish to avoid such adverse surprises from an unfortunate selection, would be better off looking at the worst case rather than the average standard deviation or variance when considering the risk reduction effect of increasing sample sizes. This is a view shared by Fung (1979). In the approach of E\&A this will be the upper bound of the spread around the average. In the case of the W\&L approach it will be the lower bound. Using this definition of risk reduction Tole finds that 25-40 securities are required to achieve a level of risk reduction within the US stock market rather than the 8-10 suggested previously.

In any case property professionals may feel that the results of simulations, even when valueweighted, are not really representative of the diversification strategies actually followed by fund managers. It may be felt that the results based on the performance of actual funds may be markedly different from the output of simulations. Indeed this seems to be the case. In particular Cullen (1991) finds that when portfolio risk, measured by standard deviation, is plotted against the number of properties within a portfolio, "volatility is not reduced as fund size increases". However when specific risk is plotted against portfolio size Cullen finds that this measure of risk does decline as fund size increases, although again the graphs display a wide variation around the average level. Cullen concludes that although large scale diversification does "appear to preclude the highest standard deviation levels" this is only achieved for portfolios of 250 properties or above. Small portfolios, with less than 100 properties, "exhibit very high volatility levels as well as very low ones". Morrell (1993a, 1997) draws similar conclusions, finding that although there is a general tendency for the largest funds to achieve high levels of risk reduction many also display high levels of specific risk. Small funds in contrast can show remarkably high levels of risk reduction even with 
relatively few properties in their portfolios. Morrell (1997) also finds that the average systematic risk $\left(\mathrm{R}^{2}\right)$ in the 162 portfolios analysed was only $81 \%$, with a quarter of the funds having $\mathrm{R}^{2}$ values less than $76 \%$. Thus work on actual property portfolios shows that the theoretical benefits to portfolio risk of increasing portfolio size are difficult to achieve in practice.

In the light of this work and the criticisms of Tole (1982) any analysis needs if possible to be based on the risk levels of actual portfolios rather than averaged simulated results in order to obtain a better representation of the impact of portfolio size on portfolio risk levels. This study investigates whether it is possible to achieve a reduction in portfolio risk down to that of the market and the number of properties needed to obtain this level using actual property portfolios over the period 1981-1996.

\section{Data}

The data used in this paper come from two sources. First the IPD Annual Digest and second the Local Markets Report (Investment Property Databank (IPD), 1998). These sources offer different levels of aggregation of the individual property data upon which the results are based, to protect confidentiality. The IPD database, at the end of 1998, contained 13,933 properties with an aggregate value of $£ 75.3 \mathrm{bn}$. The data in the Local Markets Report provide the lowest level of published aggregation within the IPD database. The data consist of the total returns on properties in the three sectors, Retail, Office and Industrial at various locations, giving a total of 392 property portfolios. The locations are based for the most part on local authority boundaries drawn up in the 1992 Local Government Act. These individual local authority portfolios were combined into mixed-town level property portfolios on a value-weighted basis to form 111 portfolios. In contrast the Annual Digest presents the results of the UK real estate market in a number of aggregations. First by the three property types; Offices, Retail and Industrial, across the standard regions of the UK, with further divisions for the London area to account for the dominance of this region in UK property funds. These are 41 different property portfolios. These individual property types were combined into 12 mixed-property portfolios. Secondly by 28 market segments, as used by IPD to analysis portfolio performance. The highest level of aggregation is into the three property types, Retail, Office and Industrial. In total therefore the analysis presented below is based on 587 property portfolios varying in size from 6 to 6806 individual properties. The summary statistics are presented in Table 1.

This table prompts the following comments. First as the level of aggregation increases the data do show a fall in total risk (variance) towards the market level, but the decline is small and depressingly slow. So for example even at the highest levels of aggregation there is still some way to go to reach the market risk level, implying that property funds managers are likely to require very large numbers of properties to attain the level of risk of the market. Although the spread of the data, as measured by the range (max-min), around the average level of total risk declines with the increase in aggregation, again the data still show a large amount of variability at even the highest levels of aggregation. Even on this basis there can be little confidence on the part of property fund managers that their portfolio will behave like the average, as suggested by Tole (1982). The level of market risk (R-squared) within the lowest aggregated or Local Market data is very variable from almost zero to over 90 per cent. This indicates that the market explains very little the variability in property returns at an individual level, hence the variability of individual property returns is mainly due to their unique or specific factors: location, location and location. Even so as portfolio size increases average R-squared values also increase as the influence of the market on portfolio returns begins to bite. Nonetheless the impact of the market even on the highest aggregated portfolios is still low compared with the impact of a stock market index on equity portfolios. This being so, property portfolios are unlikely to be able to track the returns of the market, especially if they are small sized 
portfolios of less than say, 100 properties. Finally it will be noticed that the amount of specific risk in the portfolios tends to decline with increased portfolio size but again the effect is slow and the data still displays large levels of variability in even the largest aggregated data. The following section analyses these effects in more detail. 
Table 1: Summary Statistics for the Portfolio Sub-divisions

\begin{tabular}{|c|c|c|c|c|c|c|c|c|c|c|c|c|c|}
\hline \multirow[b]{2}{*}{ Sub-Divisions } & \multirow{2}{*}{$\begin{array}{c}\text { Number of } \\
\text { Portfolios }\end{array}$} & \multicolumn{3}{|c|}{ Number of Properties } & \multicolumn{3}{|c|}{ Total Risk } & \multicolumn{3}{|c|}{ R-squared } & \multicolumn{3}{|c|}{ Specific Risk } \\
\hline & & Max & Min & Average & Max & Min & Average & Max & Min & Average & Max & Min & Average \\
\hline \multicolumn{14}{|c|}{ Local Market Data } \\
\hline Retail & 206 & 285 & 6 & 24 & 6.90 & 3.65 & 4.59 & 88.54 & 16.87 & 58.94 & 6.26 & 2.41 & 3.62 \\
\hline Office & 93 & 403 & 6 & 32 & 6.31 & 3.92 & 4.99 & 91.12 & 0.31 & 67.51 & 5.32 & 2.08 & 3.74 \\
\hline Industrial & 93 & 60 & 6 & 17 & 5.96 & 4.16 & 5.07 & 92.97 & 0.27 & 64.62 & 5.54 & 2.29 & 3.90 \\
\hline Mixed & 111 & 300 & 19 & 64 & 5.34 & 3.55 & 4.60 & 94.76 & 1.08 & 75.93 & 4.42 & 1.74 & 3.04 \\
\hline \multicolumn{14}{|l|}{ Annual Data } \\
\hline \multicolumn{14}{|c|}{ Standard Regions } \\
\hline Retail & 14 & 1570 & 25 & 465 & 5.34 & 3.88 & 4.29 & 86.76 & 48.55 & 75.75 & 3.61 & 2.14 & 2.79 \\
\hline Office & 16 & 920 & 23 & 265 & 5.61 & 3.13 & 4.79 & 92.98 & 19.45 & 64.44 & 4.22 & 2.52 & 3.51 \\
\hline Industrial & 11 & 754 & 23 & 192 & 5.22 & 3.89 & 4.84 & 83.11 & 12.42 & 50.51 & 4.73 & 3.11 & 4.01 \\
\hline Mixed & 12 & 3182 & 48 & 895 & 5.05 & 3.27 & 4.31 & 96.71 & 44.81 & 73.46 & 3.49 & 1.64 & 2.75 \\
\hline Segments & 28 & 5510 & 25 & 914 & 5.40 & 3.81 & 4.53 & 97.51 & 42.54 & 74.46 & 4.16 & 1.34 & 3.01 \\
\hline Sector Data & & \multicolumn{3}{|c|}{ Number of Properties } & \multicolumn{3}{|c|}{ Total Risk } & \multicolumn{3}{|c|}{ R-squared } & \multicolumn{3}{|c|}{ Specific Risk } \\
\hline Retail & 1 & \multicolumn{3}{|c|}{6806} & \multicolumn{3}{|c|}{4.17} & \multicolumn{3}{|c|}{88.02} & \multicolumn{3}{|c|}{2.05} \\
\hline Office & 1 & \multicolumn{3}{|c|}{4362} & \multicolumn{3}{|c|}{5.02} & \multicolumn{3}{|c|}{97.66} & \multicolumn{3}{|c|}{1.26} \\
\hline Industrial & 1 & \multicolumn{3}{|c|}{2174} & \multicolumn{3}{|c|}{4.84} & \multicolumn{3}{|c|}{75.67} & \multicolumn{3}{|c|}{3.43} \\
\hline
\end{tabular}




\section{Analysis and Results}

The average number of properties in each portfolio was calculated over the whole period from 1981 to 1996. This portfolio size data was compared with three measures of risk. The first of these was total risk (variance in log form). Secondly a measure of market risk, the coefficient of determination $\left(\mathrm{R}^{2}\right)$, of each portfolio was calculated relative to the IPD Annual Index. Finally non-market risk, or residual variance (in log form), was calculated using the following equation:

$$
\operatorname{RVar}_{\mathrm{i}}=\operatorname{Var}\left(\mathrm{R}_{\mathrm{i}}\right)-\beta_{\mathrm{i}}^{2} \operatorname{Var}\left(\mathrm{R}_{\mathrm{m}}\right)
$$

where:

$$
\begin{aligned}
& \operatorname{RVar}_{\mathrm{i}} \text { is the residual or unsystematic variance of portfolio } i \text {; } \\
& \operatorname{Var}\left(R_{i}\right) \text { is the variance of returns for portfolio } i \text {; } \\
& \operatorname{Var}\left(R_{m}\right) \text { is the variance of market returns and } \\
& \beta_{i} \text { is the slope of the regression of return of portfolio } i \text { on the returns of the } \\
& \text { market using equation (6). }
\end{aligned}
$$

A regression of $\mathrm{RVar}_{i}$ on the number of properties was then made, as in equation (9), to measure the risk reduction as portfolio size increases:

$$
\operatorname{RVar}_{\mathrm{i}}=\alpha+\beta(1 / \mathrm{N})
$$

Using the data for the 587 portfolios, Figure 1 shows the impact of portfolio size on total risk (variance in $\log$ form $)^{2}$. As will be readily appreciated there is a great deal of variability in the variance especially at low portfolio sizes, i.e. less than 100 properties. Also, as the number of properties within the portfolios increases, there is only a minor reduction in portfolio risk. Indeed there are a number of portfolios with portfolio sizes in the hundreds that show higher levels of risk than for portfolios of less than 50 properties. This supports the conclusions of Cullen (1991) and Morrell (1993a, 1997) that portfolio risk has little to do with the number of properties in the portfolio. Figures 2 and 3 present much the same picture. Although on average it may be true, portfolio size does not necessarily lead to a reduction in portfolio risk in all circumstances. This has important ramifications for fund management as it implies that two funds with the same number of properties are more than likely to have widely differing levels of risks (variance) even for portfolios of hundreds of properties. Even so, increasing the number of properties within a portfolio into the thousands is unlikely to do much to increase their level of confidence.

This is confirmed in Table 2 by the regressions of the three measures of portfolio risk on the average number of properties within the 587 portfolios. The regressions progress from the lowest level data sets, the individual Local Authority (LA) data to the highest levels of aggregation, the property type data, where the Overall LA1 data is the combination of the individual LA and the Overall LA2 data also includes the mixed-town data. The Overall data regression includes all the data sets.

\footnotetext{
2 In order to simplify the presentation of the data Figures 1-3 only show the data up to the 400 property level, even though the data contains portfolio sizes up to more than 6000 properties. Graphs showing the full data are available on request.
} 
The results in Table 2 show the coefficients of the regressions in equations 5, 7, and 9, together with the coefficient of determination $\left(\mathrm{R}^{2}\right)$ and the standard error of the regression. Table 1 shows that the signs of the beta coefficients are all the correct and in all but one case are significant at the 5\% level. The level of significance is particularly strong for the residual variance regressions, as suggested by portfolio theory. Risk does on average decline significantly as the number of assets in the portfolio increases. However, as will be appreciated the amount of variability explained (adjusted $\mathrm{R}^{2}$ ) by all the regressions is small and considerably below that produced by previous studies using averaged data.

Panel A of Table 2 shows the regression results for total risk on number of properties. The coefficient of determination (adjusted $\mathrm{R}^{2}$ ) is small, never more than $7.5 \%$ and can be as low as $1.3 \%$. As a result the standard errors around the regression results are very high. It is this which leaves the investor with little confidence that their portfolio will behave 'like the average'. The number of properties within a portfolio has little or no impact on the level of total risk of the portfolio, confirming the results of Cullen (1991) and Morrell (1993a, 1997).

Table 2: Results of Regression of Risk on the Number of Properties

\begin{tabular}{lcccccc}
\hline Risk & Alpha & Beta & $\begin{array}{c}\text { T-stat. } \\
\text { Alpha }\end{array}$ & $\begin{array}{c}\text { T-stat. } \\
\text { Beta }\end{array}$ & $\begin{array}{c}\text { Adjusted } \\
\text { R-Squared } \\
\text { \% }\end{array}$ & $\begin{array}{c}\text { Standard } \\
\text { Error }\end{array}$ \\
\hline Panel A: Log. & & & & & & \\
Variance & & & & & & \\
LA Retail & 4.43 & 2.65 & 70.60 & 2.99 & 3.73 & 0.45 \\
LA Office & 4.87 & 2.02 & 53.61 & 1.47 & 1.27 & 0.45 \\
LA Industrial & 4.88 & 2.43 & 52.44 & 2.26 & 4.28 & 0.38 \\
Overall LA1 & 4.60 & 3.04 & 93.11 & 4.55 & 4.80 & 0.48 \\
Overall LA2 & 4.57 & 3.36 & 127.68 & 6.22 & 6.99 & 0.45 \\
Overall & 4.56 & 3.40 & 151.54 & 6.94 & 7.45 & 0.46 \\
& & & & & & \\
Panel B: R-Squared & & & & & & \\
LA Retail & 0.71 & -1.95 & 35.21 & -6.87 & 18.38 & 0.15 \\
LA Office & 0.73 & -1.00 & 21.27 & -1.93 & 2.91 & 0.17 \\
LA Industrial & 0.70 & -0.71 & 15.70 & -1.37 & 0.93 & 0.18 \\
Overall LA1 & 0.71 & -1.33 & 41.63 & -5.77 & 7.65 & 0.17 \\
Overall LA2 & 0.75 & -1.76 & 57.93 & -9.00 & 13.78 & 0.16 \\
Overall & 0.74 & -1.69 & 67.37 & -9.45 & 13.12 & 0.17 \\
& & & & & & \\
Panel C: Residual or & & & & & & \\
Specific Risk & & & & & & \\
LA Retail & 3.17 & 7.37 & 41.02 & 6.76 & 17.92 & 0.56 \\
LA Office & 3.49 & 4.43 & 25.11 & 2.11 & 3.67 & 0.68 \\
LA Industrial & 3.51 & 5.05 & 22.14 & 2.76 & 6.70 & 0.64 \\
Overall LA1 & 3.30 & 6.40 & 52.35 & 7.50 & 12.41 & 0.61 \\
Overall LA2 & 3.09 & 8.56 & 62.97 & 11.54 & 20.86 & 0.62 \\
Overall & 3.08 & 8.80 & 73.50 & 12.90 & 22.06 & 0.63 \\
\hline
\end{tabular}


The results for the measure of systematic risk, in Panel B, are only slightly better, with the goodness of fit coefficient reaching a maximum of $14 \%$ but the lowest is less than $1 \%$, for the Industrial property data. The average $\mathrm{R}^{2}$, as indicated by the Alpha, is only $74 \%$, slightly less than that reported by Morrell (1997). As can be seen in Figure 2, there is a great deal of variability around the regression line, especially at the lower portfolio sizes. For example, at the 20 property level the R-squared values range from 0 to 92 percent. However, at approximately the 300 property level the spread is less, ranging from 56 to 95 per cent. There is a tendency for the amount of systematic risk in any portfolio to increase as the number of properties increases, but the effect is only marginal and even very small portfolios can show much higher levels of market risk than the largest portfolios. This suggests that most if not all portfolios will display high levels of tracking error, that is the variability of their portfolio returns relative to some benchmark of performance. This is likely to be the case even for portfolios of thousands of properties. The tracking errors of small portfolios are likely to be huge, even for value-weighted portfolios. Fund managers may fool themselves into thinking that they must be tracking the market if they display the same value-weighting as the market across property types and regions, when in fact they should have very little confidence that this is really the case.

In contrast the figures in Panel $\mathrm{C}$ for specific risk (residual variance in log form) show generally much stronger results, the adjusted R-squared values reaching a high of 22 per cent. Even so the results are still weak in comparison with those reported in previous work based on "averaged" simulations. Again, hundreds if not thousands of properties will be needed for fund managers to feel confident that the main influence on their portfolios returns is that of the market rather than the unique or specific factors in the property returns.

The high levels of non-market risk within even the largest portfolios suggest that the performance of a property portfolio is due to some unique or specific features (of its component parts). This has important implications for performance measurement services that try to attribute the fund manger's contribution to property portfolio performance. If the risk level of even the largest funds is a consequence of their unique characteristics, rather than the influences of the market, it becomes difficult to isolate those features of fund performance which are due to structure or policy (sector and regional weighting relative to the benchmark) and the selection or property component (the manager's skill in choosing the right property).

The regression results confirm the images presented in Figures 1 to 3 . Increasing portfolio size leads on average to a reduction in risk, however measured. But the one area where the effect is greatest is in the reduction of the specific or residual risk in the portfolio, as suggested by portfolio theory. Nonetheless the results even for the specific risk regressions are weak, confirming the findings of Tole (1982) that without the "averaging" effect typically found in simulation studies the regressions generally lack power and display large standard errors. 


\section{Conclusion}

This paper has re-evaluated the potential for risk reduction in the UK real estate market for property portfolio across the whole spectrum of portfolio sizes in numerous regions and types using actual data over the period 1981-1996.

When the full data set is used the statistical significance of the regressions of three standard measures of portfolio risk on size is greatly reduced. The results confirm the findings of Cullen (1990) and Morrell (1993a, 1997). Property portfolios of a large size, tend on average, to have lower risks than small sized portfolios, but portfolios with relatively few properties can have very high or very low risk. An individual investor who uses the advice contained in previous studies which are based on the results of average portfolios may be exposed to greater risk than they anticipate. Fund managers can have little confidence that their portfolio will display the same level of risk as the average. Their portfolio could be significantly higher or lower than they anticipated, especially at small sizes. The results suggest that for fund managers to be confident that their portfolio will have a risk level more like the average they need to hold portfolios of a considerably greater size than they might expect, or can sensibly hold. The results of previous studies which suggest that only 20-40 properties are needed to reduce the risk of a property portfolio down to the market level are a significant underestimate. The actual figure is more likely to be around 400-500 properties, a portfolio size well above that of even the largest fund in the UK. Size alone does not necessarily lead to a reduction in portfolio risk. Clearly other factors are of greater importance. 


\section{References}

Barber, C. (1991) Modern Portfolio Theory; Fact and Fantasy, A Paper presented as part of the seminar series organised by the Society of Property Researchers and the RICS, entitled Property in a Portfolio Context.

Brown, G.R. (1988) Reducing the Dispersion of Returns in UK Real Estate Portfolios, Journal of Valuation, 6, 2, 127-147.

Brown, G.R. (1991) Property Investment and the Capital Markets. E \& F.N. Spon, London.

Byrne, P.J. and Lee, S.L. (1999) Risk Reduction in the United Kingdom Property Market, Journal of Property Research, forthcoming.

Cullen, I. (1991) Risk Management in Investment Property Portfolios, Paper presented as part of the seminar series organised by the Society of Property Researchers and the RICS, entitled Property in a Portfolio Context.

Elton, E.J. and Gruber, M.J. (1977) Risk Reduction and Portfolio Size: An Analytical Solution, Journal of Business, 50, 415-437.

Evans, J.L. and Archer, S.H. (1968) Diversification and the Reduction of Dispersion: An Empirical Analysis, Journal of Finance, 23, 761-767.

Fung, W.K.H. (1979) On the Process of Risk Reduction through Diversification, Journal of Banking and Finance, 3, 2, 281-299.

IPD (1996) IPD Property Investor's Digest 1996, Investment Property Databank, London.

IPD (1998) Local Markets Report, Investment Property Databank, London.

Johnson, K.H. and Shannon, D.S. (1974) A Note on Diversification and the Reduction of Dispersion, Journal of Financial Economics, 4, 365-372.

Jones Lang Wootton (1986) Risk and Asset Allocation: Implications of Portfolio Strategy.

Lloyd, W.P., Hand, J.H. and Modani, N.K. (1981) The Effect of Portfolio Construction Rules on the Relationship Between Portfolio Size and Effective Diversification, Journal of Financial Research, 4, 183-193.

Morrell, G.D. (1993a) Fund Structure or Stock Selection? A Decomposition of Relative Returns in the UK Property Market, A Paper presented to the Second IPD Investment Strategies Conference, 17-18 November, Brighton.

Morrell, G.D. (1993b) Value-weighting and the Variability of Real Estate Returns: Implications for Portfolio Construction and Performance Evaluation, Journal of Property Research, 10, 167-183.

Morrell, G.D. (1997) Property Risk and Portfolio Construction, A Paper presented to the Sixth IPD Investment Strategies Conference, 27-28 November, Brighton. 
Myer, F.C.N., Webb, J.R. and Young, M. (1997) Issues in Diversification for Real Estate, A Paper presented to the ARES Conference, Monterey, California, April.

Newbould, G.D. and Poon, P.S. (1993) The Minimum Number of Stocks Needed for Diversification, Financial Practice and Education, 3, 85-87.

Schuck, E.J. and Brown, G.R. (1997) Value Weighting and Real Estate Risk, Journal of Property Research, 14, 3, 169-188.

Tole, T. (1982) You Can't Diversify Without Diversifying, Journal of Portfolio Management, 8, 5-11.

Wagner, W.H. and Lau, S.C. (1971) The Effect of Diversification on Risk, Financial Analysts Journal, 27, 48-53. 
Figure 1: Average Number of Properties and Portfolio Variance

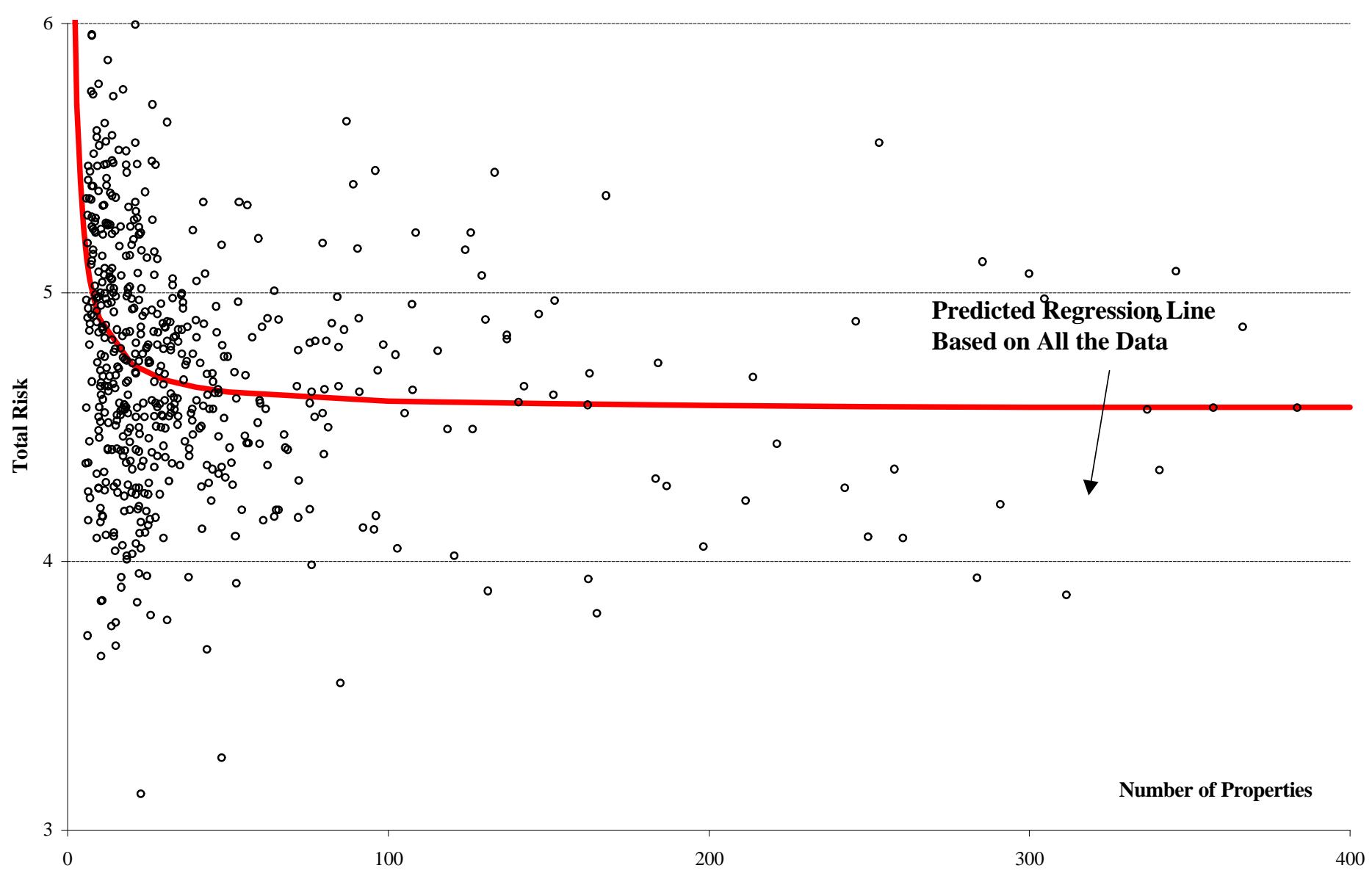


Figure 2 Average Number of Properties and R-Squared

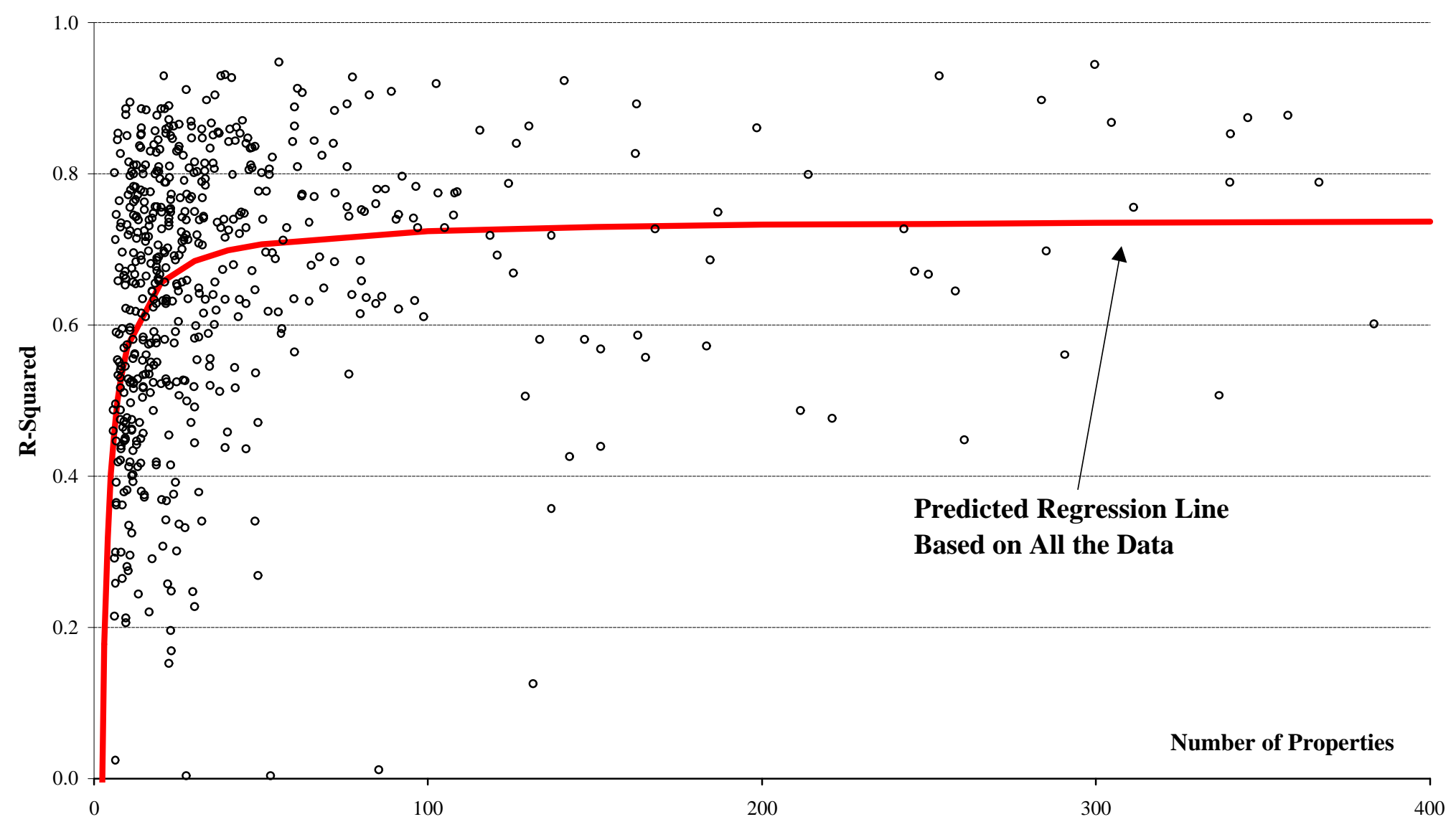


Figure 3 Average Number of Properties and Specific Risk

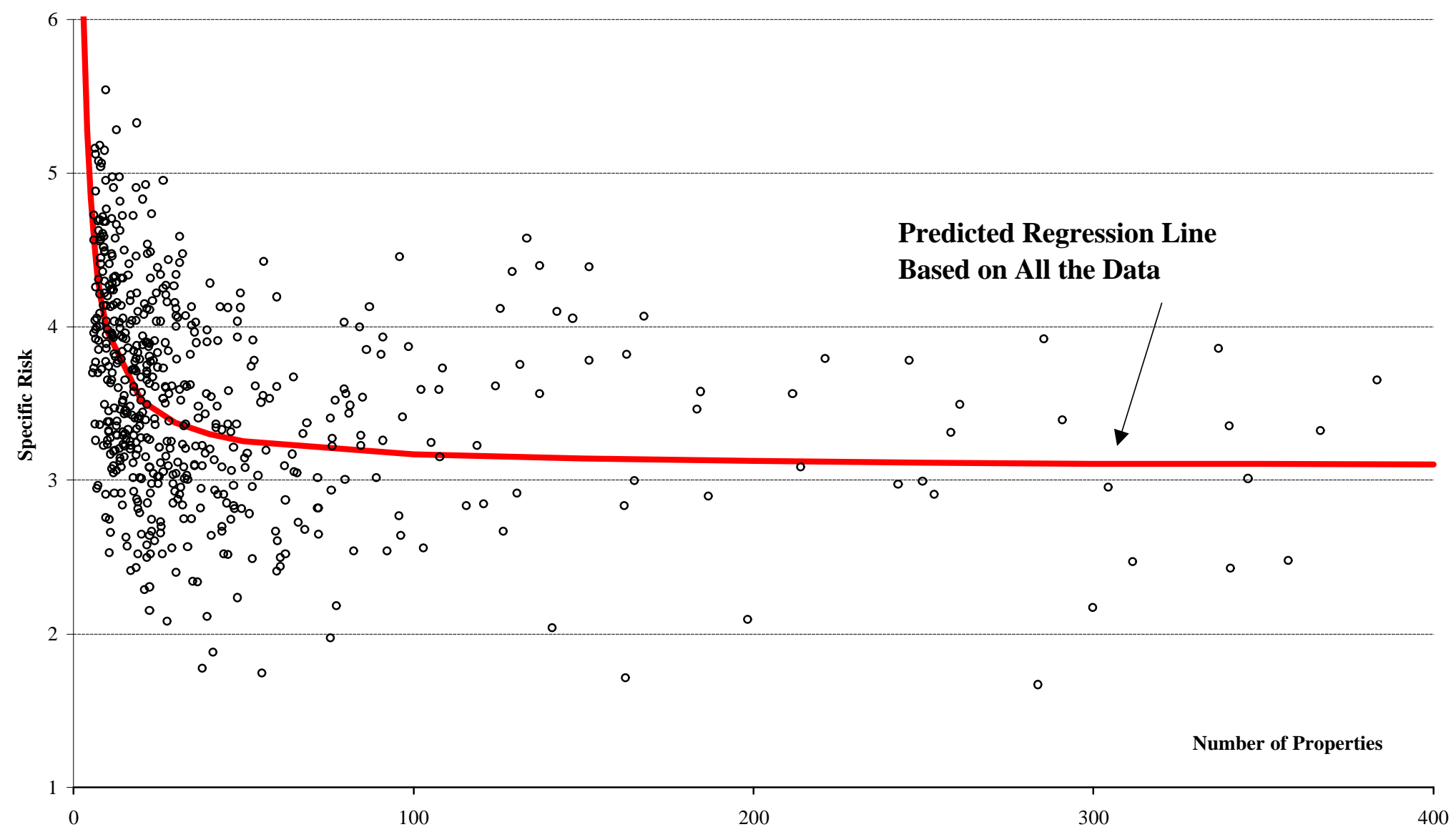

